\title{
Comparative Study of Maternal and Fetal Outcome between Low and Normal Amniotic Fluid Index
}

\author{
Dr. Swati ${ }^{1}$, Dr. Lila Vyas ${ }^{2 *}$ \\ ${ }^{1}$ Resident, ${ }^{2}$ Senior Professor, Department of Obstetrics \& Gynaecology SMS Medical College, Jaipur, Rajasthan, India
}

\begin{abstract}
DOI: 1 10.36348/sijog.2019.v02i11.004 $\quad$ | Received: 31.10 .2019 | Accepted: 07.11.2019| Published: 12.11 .2019
\end{abstract}
*Corresponding author: Dr. Lila Vyas

Abstract

Background: Amniotic fluid is a clear, slightly yellowish liquid that surrounds the fetus during pregnancy. It is contained in the amniotic sac. During pregnancy, it acts as a shock absorber, maintains even temperature, allows for growth and free movement of the fetus and prevents adhesion between fetal parts and amniotic sac. The aim was to study fetal and maternal out come in cases of low AFI and normal AFI. Methods: A hospital based Prospective comparative study was conducted in the Department of Obstetrics and Gynaecology, SMS Medical College, Jaipur from April 2017 to September 2018. Study conducted on 110 pregnant women at term (37-40 weeks) attending antenatal clinic. They were divided in to two groups. Group-A comprising 55 patients with AFI $>5 \mathrm{~cm}$ and Group-B comprising 55 Patients with AFI less than $5 \mathrm{~cm}$ or equal to $5 \mathrm{~cm}$. Results: In our study, Out of 55 oligohydramnios patients, 43.64\%(24) were induced, $27.27 \%$ (15) were augmented \& 29.09\%(16) were left for spontaneous progression of labor \& out of 55 normal AFI patients $58.18 \%(32)$ patients were induced, 29.09\%(16) were augmented, $12.73 \%(7)$ were left for spontaneous progression of labor. Mean Apgar score at $1 \& 5$ minute of birth is comparatively low in oligohydramnios patient \& nursery admission was more, but only short term neonatal morbidity was seen. No long term consequences were present in these babies. Conclusion: An AFI $\leq 5 \mathrm{~cm}$ detected at term that was at or after 37 completed weeks of gestation in a low risk pregnancy was an indicator of poor perinatal outcome. Oligohydramnios was being detected more frequently nowadays due to ready availability of ultrasonography these days.

Keywords: AFI, Fetal and maternal outcome, Oligohydramnios.

Copyright @ 2019: This is an open-access article distributed under the terms of the Creative Commons Attribution license which permits unrestricted use, distribution, and reproduction in any medium for non-commercial use (NonCommercial, or CC-BY-NC) provided the original author and source are credited.

\section{INTRODUCTION}

Amniotic fluid is a clear, slightly yellowish liquid that surrounds the fetus during pregnancy. It is contained in the amniotic sac. During pregnancy, it acts as a shock absorber, maintains even temperature, allows for growth and free movement of the fetus and prevents adhesion between fetal parts and amniotic sac. During labour, the amnion and chorion are combined to form a hydrostatic wedge which helps in dilatation of cervix, it guards against umbilical cord compression. When the volume of amniotic fluid is decreased, it is termed as oligohydramnios. Oligohydramnios is a common complication of pregnancy and its incidence is $3.9 \%$ of total pregnancy at term. Low amniotic fluid has been associated with increased risk of maternal morbidity in terms of increased rate of induction of labour and operative interventions, and intrauterine growth retardation, meconium aspiration syndrome, birth asphyxia, low APGAR scores, and congenital anomalies [1].

Many studies show that oligohydramnios is associated with a variety of ominous pregnancy outcomes, such as fetal distress, low birth weight, perinatal morbidity, perinatal mortality and increased incidence of cesarean section[2-5].

However, some studies show that AFI is a poor predictor of adverse outcome, and even the existence of an entity like isolated term oligohydramnios has been questioned by some authors. Thus, this study is conducted to determine whether an antepartum AFI of $5 \mathrm{~cm}$ or less as a predictor of adverse pregnancy outcome [6-8]. 


\section{MATERIALS AND METHODS}

This prospective case-control study consists of an analysis of pregnancy outcome in 55 cases with diagnosis of oligohydramnios $(\mathrm{AFI}<5)$ by ultrasound after 37 completed weeks of gestation compared with 55 controls with no oligohydramnios (AFI more than 8) and matched for other variables such as age, parity, gestational age and any pregnancy complication. Consent from the patient was taken and ethical clearance taken from the Ethical Committee.

For all the selected cases, thorough history was taken, and complete examination was done. Clinical evidence of oligohydramnios was looked for. The previous obstetric records and ultrasound reports were reviewed.

For all the women, ultrasound examination was done, and AFI was calculated by four quadrant amniotic fluid volume measurement technique. For all women baseline investigations like hemoglobin\%, blood group and $\mathrm{RH}$ typing, urine examination was done. Non-stress test (NST) was done for all patients.

Oligohydramnios is defined as AFI $\leq 5 \mathrm{~cm}$. The amniotic fluid volume is considered normal if AFI is between $5.1 \mathrm{~cm}$ and $20 \mathrm{~cm}$. For each case a control was taken with similar gravidity, parity, gestational age but the AFI of more than $8 \mathrm{~cm}$ and $<20 \mathrm{~cm}$.

\section{Inclusion criteria}

1. $\mathrm{AFI} \leq 5$

2. Single live intrauterine gestation with cephalic presentation

3. 37 completed weeks of gestation

4. Intact membrane.

\section{Exclusion criteria}

1. AFI more than 5

2. Gestational age $<37$ weeks

3. Post-term

4. Associated fetal malformations

5. Ruptured membranes Malpresentation and multiple gestation

6. High-risk pregnancy

7. Uterine scar due to previous lower segment caesarean section (LSCS), myomectomy, hysterotomy

8. To collect required information from eligible patients a pre-structured pre-tested proforma will be used.

For data analysis Microsoft excel was used and data were analyzed with the help of frequencies, figures, proportions, measures of central tendency. Chisquare test was use for qualitative data and t-test was used for quantitative data.

\section{RESULTS}

The mean age in Group-A in our study was $24.27 \pm 3.98$ years and in Group-B it was $25.26 \pm 3.64$ years. Group-A had $54.55 \%$ unbooked patients, and $45.45 \%$ booked patients and Group-B had $52.73 \%$ unbooked patients and $47.27 \%$ booked patients there was no statistical difference between the two groups.

In the present study was gravida $1-58.2 \%$, gravida $2-32.7 \%, \geq$ gravida $3-9.1 \%$ in the Group-A. In Group-B, gravida 1 were $51 \%$, gravida 2 were $27.3 \%$, $\geq$ and gravida 3 were $21.8 \%$.

Table-1: Comparison of AFI in Group-A and Group-B

\begin{tabular}{|l|l|l|l|l|l|}
\hline \multirow{3}{*}{ AFI } & \multicolumn{2}{|l|}{ Group-A (n=55) } & \multicolumn{2}{l|}{ Group-B (n=55) } & \multirow{2}{*}{ p- value } \\
\cline { 2 - 5 } & Mean \pm SD & Median (IQR) & Mean \pm SD & Median $(\mathrm{IQR})$ & \\
\cline { 2 - 5 } & $8.35 \pm 1.43$ & $8(7-10)$ & $2.63 \pm 0.98$ & $3(2-3)$ & $<.0001$ \\
\hline
\end{tabular}

In our study, as controls, patients with $\mathrm{AFI}>5$ were taken in Group A, where mean AFI was $8.35 \pm$ 1.43 and cases of oligohydramnios (AFI $>5$ ) were taken in Group-B where mean AFI was $2.63 \pm 0.98$. There was significant difference between the two groups $(\mathrm{P}<0.05)$.

Table-2: Comparison of Induction / Spontaneous / Augmentation in Group-A and Group-B

\begin{tabular}{|l|l|l|l|l|}
\hline Induction / Spontaneous / Augmentation & Group-A & Group-B & Total & p-value \\
\hline Induction & $32(58.18 \%)$ & $24(43.64 \%)$ & $56(50.91 \%)$ & \\
\hline Spontaneous & $7(12.73 \%)$ & $16(29.09 \%)$ & $23(20.91 \%)$ & \\
\hline Augmentation & $16(29.09 \%)$ & $15(27.27 \%)$ & $31(28.18 \%)$ & 0.096 \\
\hline Total & $55(100.00 \%)$ & $55(100.00 \%)$ & $110(100.00 \%)$ & \\
\hline
\end{tabular}

In our study, delivery was induced in $58.18 \%$ patients in Group-A and in $43.64 \%$ patients in Group-B; delivery was augmented in $29.09 \%$ patients in Group-A and in $27.27 \%$ patients in Group-B; and delivery was spontaneous in $12.73 \%$ patients in Group-A and in $29.09 \%$ patients in Group-B. There was no statistical difference between the two groups on the comparison in mode of delivery ( $p$-value>0.05). 
Swati \& Lila Vyas; Sch Int J Obstet Gynec, Nov. 2019; 2(11): 272-276

Table-3: Comparison of Mode of Delivery in Group-A and Group-B

\begin{tabular}{|l|l|l|l|l|}
\hline Mode of Delivery & Group-A & Group-B & Total & p-value \\
\hline LSCS & $18(32.73 \%)$ & $30(54.55 \%)$ & $48(43.64 \%)$ & \multirow{2}{*}{0.021} \\
\hline Normal Delivery & $37(67.27 \%)$ & $25(45.45 \%)$ & $62(56.36 \%)$ & \\
\hline Total & $55(100.00 \%)$ & $55(100.00 \%)$ & $110(100.00 \%)$ & \\
\hline
\end{tabular}

In our study, for mode of delivery, LSCS was used in $18(32.73 \%)$ patients in Group-A and in 30 $(54.55 \%)$ patients in Group-B; and normal delivery was in $37(67.27 \%)$ patients in Group-A and in $25(45.45 \%)$ patients in Group-B. There was significant difference between the two groups with respect to mode of delivery $(\mathrm{p}<0.05)$
Caesarean sections were more common in Oligohydramnios patients because of more incidence of fetal distress \& non progression of labor in these patients.

Table-4: Comparison of Birth Weight (in kg) in Group-A and Group-B

\begin{tabular}{|l|l|l|l|l|}
\hline $\begin{array}{l}\text { Birth Weight } \\
\text { (in kg) }\end{array}$ & Group-A & Group-B & Total & \multirow{2}{*}{ p-value } \\
\hline$<2.5$ & $3(5.45 \%)$ & $5(9.09 \%)$ & $8(7.27 \%)$ & \multirow{2}{*}{0.716} \\
\hline$\geq 2.5$ & $52(94.55 \%)$ & $50(90.91 \%)$ & $102(92.73 \%)$ & \\
\hline Total & $55(100.00 \%)$ & $55(100.00 \%)$ & $110(100.00 \%)$ & \\
\hline Mean \pm SD & $2.73 \pm 0.21$ & $2.74 \pm 0.21$ & $2.74 \pm 0.21$ & \multirow{2}{*}{0.788} \\
\hline Median (IQR) & $2.7(2.600-2.900)$ & $2.7(2.600-2.900)$ & $2.7(2.600-2.900)$ & \\
\hline
\end{tabular}

The mean birth weight in Group-A was $2.73 \pm$ $0.21 \mathrm{kgs}$ and in Group- B was $2.74 \pm 0.21 \mathrm{kgs}$. On categorisation, among cases, maximum patients i.e. 52 $(94.55 \%)$ were $\geq 2.5 \mathrm{kgs}$ followed by $3(5.45 \%)<2.5$ kgs. Among the controls also, maximum patients i.e. 50
$(90.91 \%)$ were $\geq 2.5 \mathrm{kgs}$ followed by $5(9.09 \%)<2.5$ kgs. There was no statistical difference between the mean birth weight and birth weight distribution of cases and controls $(\mathrm{p}>0.05)$.

Table-5: Comparison of Meconium Stained Liquor in Group-A and Group-B

\begin{tabular}{|l|l|l|l|l|}
\hline Meconium Stained Liquor & Group-A & Group-B & Total & \multirow{2}{*}{ p-value } \\
\hline No & $45(81.82 \%)$ & $27(49.09 \%)$ & $72(65.45 \%)$ & \multirow{2}{*}{0.0003} \\
\hline Yes & $10(18.18 \%)$ & $28(50.91 \%)$ & $38(34.55 \%)$ & \\
\hline Total & $55(100.00 \%)$ & $55(100.00 \%)$ & $110(100.00 \%)$ & \\
\hline
\end{tabular}

Above table shows data of meconium stained liquor .In our study, in Group-A, Meconium stained liquor (MSL) was seen in $18.18 \%$ patients whereas in
Group-B it was seen in $50.91 \%$ patients. There was significant difference between the two groups $(\mathrm{p}<0.05)$.

Table-6: Comparison of APGAR at 1 Min and 5 Min in Group-A and Group-B

\begin{tabular}{|l|l|l|l|l|l|}
\hline & \multicolumn{2}{|l|}{ Group-A $(\mathbf{n}=\mathbf{5 5})$} & \multicolumn{2}{l|}{ Group-B $(\mathbf{n}=\mathbf{5 5})$} & \multirow{2}{*}{ p- value } \\
\cline { 2 - 5 } & Mean $\mathbf{\pm}$ SD & Median $(\mathbf{I Q R})$ & Mean $\pm \mathbf{S D}$ & Median $(\mathbf{I Q R})$ & \\
\hline APGAR at 1 Min & $6.76 \pm 0.54$ & $7(7-7)$ & $6.09 \pm 1.21$ & $6(6-7)$ & 0.0001 \\
\hline APGAR at 5 Min & $6.8 \pm 0.45$ & $7(7-7)$ & $6.31 \pm 1.14$ & $7(6-7)$ & 0.002 \\
\hline
\end{tabular}

Above table shows APGAR score at 1 min \& 5 min . In Group-A, mean APGAR score at 1 minute was and at 5 minutes was $6.76 \pm 0.54,6.8 \pm 0.45$ and in Group-B it was $6.09 \pm 1.21,6.31 \pm 1.14$ at 1 minute and at 5 minutes. There was significant difference between the two groups $(\mathrm{p}<0.05)$.

APGAR score at 1 and 5 minutes was lower in cases of oligohydramnios as compared to controls.

Table-7: Comparison of Nursery Admission in Group-A and Group-B

\begin{tabular}{|l|l|l|l|l|}
\hline NICU Admission & Group-A & Group-B & Total & p-value \\
\hline No & $45(81.82 \%)$ & $27(49.09 \%)$ & $72(65.45 \%)$ & \multirow{2}{*}{0.0003} \\
\hline Yes & $10(18.18 \%)$ & $28(50.91 \%)$ & $38(34.55 \%)$ & \\
\hline Total & $55(100.00 \%)$ & $55(100.00 \%)$ & $110(100.00 \%)$ & \\
\hline
\end{tabular}

Above table tells that, in Group-A, NICU admission was required in $18.18 \%$ whereas in Group-B it was required in $50.91 \%$ patients. There was significant difference between the two groups $(\mathrm{p}<0.05)$. 


\section{DISCUSSION}

In our study, as controls, patients with $\mathrm{AFI}>5$ were taken in Group A, where mean AFI was $8.35 \pm$ 1.43 and cases of oligohydramnios (AFI $>5$ ) were taken in Group-B where mean AFI was $2.63 \pm 0.98$. There was significant difference between the two groups $(\mathrm{P}<0.05)$.

In the study by Tajinder et al. the mean AFI in the study group (AFI=5) was $3.605 \pm 1.1490 \mathrm{~cm}$ and in control group (AFI >5) was $12.001 \pm 3.520 \mathrm{~cm}$. In Driggers et al. [9] the mean AFI in cases was $3.0 \pm 1.5$ $\mathrm{cm}$ and in controls was $10.7 \pm 4.0 \mathrm{~cm}$; which were similar to our study.

In our study, delivery was induced in $58.18 \%$ patients in Group-A and in $43.64 \%$ patients in Group-B; delivery was augmented in $29.09 \%$ patients in Group-A and in $27.27 \%$ patients in Group-B; and delivery was spontaneous in $12.73 \%$ patients in Group-A and in $29.09 \%$ patients in Group-B. There was no statistical difference between the two groups on the comparison in mode of delivery ( $\mathrm{p}$-value $>0.05$ ).

Similar findings were seen in other studies by Ahmar et al. Tajinder et al. Biradar et al. [10]. Showed more induction in patients as compared to controls because of abnormal Doppler and/or medical/obstetric complications (like eclampsia, pre-eclampsia, GDM) and because pregnancies were not allowed to continue beyond 37 weeks in these patients.

In our study, for mode of delivery, LSCS was used in $18(32.73 \%)$ patients in Group-A and in 30 $(54.55 \%)$ patients in Group-B; and normal delivery was in $37(67.27 \%)$ patients in Group-A and in $25(45.45 \%)$ patients in Group-B. There was significant difference between the two groups with respect to mode of delivery $(\mathrm{p}<0.05)$.

Caesarean sections were more common in Oligohydramnios patients because of more incidence of fetal distress \& non progression of labor in these patients.

Golan A et al. [11] found that, the caesarean section was performed in $35.2 \%$ of pregnancies. In study done by Bansal D et al.[12], the caesarean section was performed in $47 \%$ of patients.

The mean birth weight in Group-A was $2.73 \pm$ $0.21 \mathrm{kgs}$ and in Group- B was $2.74 \pm 0.21 \mathrm{kgs}$. On categorisation, among cases, maximum patients i.e. 52 $(94.55 \%)$ were $\geq 2.5 \mathrm{kgs}$ followed by $3(5.45 \%)<2.5$ kgs. Among the controls also, maximum patients i.e. 50 $(90.91 \%)$ were $\geq 2.5 \mathrm{kgs}$ followed by $5(9.09 \%)<2.5$ kgs. There was no statistical difference between the mean birth weight and birth weight distribution of cases and controls $(\mathrm{p}>0.05)$.
We found that birth weight of the baby was not affected by Oligohydramnios. In the study by Ahmar et al. [13], the mean birth weight of the babies in the study group was $2480 \pm 120 \mathrm{~g}$ and in the control group it was $2770 \pm 150 \mathrm{~g}$ which was comparable to our study. They also showed that Oligohydramnios did not have adverse effect on the outcome of the baby.

In contrast to our study, Tajinder et al. [14] showed that among Oligohydramnios cases, 57\% patients had baby weights less than $2.0 \mathrm{~kg}$. In $16 \%$ patients birth weights were between $2.0-2.9 \mathrm{~kg}$, in $23 \%$ between $3.0-3.9 \mathrm{~kg}$ and in $4 \%$ patients baby weight was $\geq 4 \mathrm{kgs}$. In the control group, $24 \%$ patients had birth weights less than $2.0 \mathrm{~kg}$. $42 \%$ patients had baby weights between $2.0-2.9 \mathrm{~kg}, 30 \%$ patients between $3.0-3.9 \mathrm{~kg}$ and in $4 \%$ patient's baby weight was $\geq 4 \mathrm{kgs}$. The mean birth weight of the study group was $2.37 \pm 0.77 \mathrm{~kg}$ and of the control group was $2.70 \pm 0.68 \mathrm{~kg}$. The difference was statistically significant $(\mathrm{p}<0.05)$.

APGAR score at $1 \mathrm{~min} \& 5 \mathrm{~min}$. In Group-A, mean APGAR score at 1 minute was and at 5 minutes was $6.76 \pm 0.54,6.8 \pm 0.45$ and in Group-B it was 6.09 $\pm 1.21,6.31 \pm 1.14$ at 1 minute and at 5 minutes. There was significant difference between the two groups $(\mathrm{p}<0.05)$.

APGAR score at 1 and 5 minutes was lower in cases of oligohydramnios as compared to controls. In contrast Ahmar et al. [13] showed comparable APGAR scores in the cases and controls.

Sarno et al. [15] noted a significantly higher rate of fetal distress \& low APGAR score in women with oligohydramnios. This is reported to be due to head \& cord compression. Dissimilarities between the above mentioned results could be due to better intrapartum fetal assessment facilities.

In Group-A, NICU admission was required in $18.18 \%$ whereas in Group-B it was required in $50.91 \%$ patients. There was significant difference between the two groups $(\mathrm{p}<0.05)$.

The cases of oligohydramnios required more Nursery admissions because all low birth weight babies $(<2.0 \mathrm{~kg})$, and babies with birth asphyxia \& low Apgar score were admitted to Nursery. In all cases of nursery admission, only short term neonatal morbidity was seen.

In the study by Tajinder et al. [14], 65 (65\%) babies in the study group (AFI=5) were admitted in NICU as compared to $28(28 \%)$ babies in the control group (AFI >5). This difference was statistically significant in this study $\mathrm{p}=0.00$. 


\section{CONCLUSSION}

An AFI $\leq 5 \mathrm{~cm}$ detected at term that was at or after 37 completed weeks of gestation in a low risk pregnancy was an indicator of poor perinatal outcome. Oligohydramnios was being detected more frequently now-adays due to ready availability of ultrasonography these days

\section{REFERENCES}

1. Mathuriya, G., Verma, M., Rajpoot, S. (2017). Comparative study of maternal and fetal outcome between low and normal amniotic fluid index at term. Int J Reprod Contracept Obstet Gynecol, 6:640-4.

2. Divon, M. Y., Marks, A. D., \& Henderson, C. E. (1995). Longitudinal measurement of amniotic fluid index in postterm pregnancies and its association with fetal outcome. American journal of obstetrics and gynecology, 172(1), 142-146.

3. Grubb, D. K., \& Paul, R. H. (1992). Amniotic fluid index and prolonged antepartum fetal heart rate decelerations. Obstetrics and gynecology, 79(4), 558-560.

4. Chauhan, S. P., Sanderson, M., Hendrix, N. W., Magann, E. F., \& Devoe, L. D. (1999). Perinatal outcome and amniotic fluid index in the antepartum and intrapartum periods: a metaanalysis. American journal of obstetrics and gynecology, 181(6), 1473-1478.

5. Leeman, L., \& Almond, D. (2005). Isolated oligohydramnios at term: is induction indicated. $J$ Fam Pract, 54(1), 25-32.

6. Schucker, J. L., Mercer, B. M., Audibert, F., Lewis, R. L., Friedman, S. A., \& Sibai, B. M. (1996). Serial amniotic fluid index in severe preeclampsia: a poor predictor of adverse outcome. American journal of obstetrics and gynecology, 175(4), 10181023.

7. Conway, D. L., Adkins, W. B., Schroeder, B., \& Langer, O. (1998). Isolated oligohydramnios in the term pregnancy: is it a clinical entity?. Journal of Maternal-Fetal Medicine, 7(4), 197-200.
8. Magann, E. F., Chauhan, S. P., Kinsella, M. J., McNamara, M. F., Whitworth, N. S., \& Morrison, J. C. (1999). Antenatal testing among 1001 patients at high risk: the role of ultrasonographic estimate of amniotic fluid volume. American journal of obstetrics and gynecology, 180(6), 1330-1336.

9. Driggers, R. W., Holcroft, C. J., Blakemore, K. J., \& Graham, E. M. (2004). An amniotic fluid index $\leq$ $5 \mathrm{~cm}$ within 7 days of delivery in the third trimester is not associated with decreasing umbilical arterial $\mathrm{pH}$ and base excess. Journal of perinatology, 24(2), 72.

10. Ghosh, R., Oza, H., \& Padhiyar, B. Maternal and fetal outcome in oligohydramnios: study from a tertiary care hospital, Ahmedabad, India. International Journal of Reproduction, Contraception, Obstetrics and Gynecology, 7(3), 908.

11. Golan, A., Lin, G., Evron, S., Arieli, S., Niv, D., \& David, M. P. (1994). Oligohydramnios: maternal complications and fetal outcome in 145 cases. Gynecologic and obstetric investigation, 37(2), 91-95.

12. Bansal, D., \& Deodhar, P. (2015). A Clinical Study of Maternal and Perinatal Outcome i n Oligohydramnios. J Res Med Den Sci, 3(4), 312316.

13. Ahmar, R., Parween, S., Kumari, S., \& Kumar, M. (2018). Neonatal and maternal outcome in oligohydramnios: a prospective study. International Journal of Contemporary Pediatrics, 5(4), 1409.

14. Tajinder, K., \& Ruchika, S. (2016). Feto-Maternal Outcome in Pregnancies with Abnorma 1 AFI. IOSR Journal of Dental and Medical Sciences, 15(4), 71-75.

15. Sarno, J. A., Ahn, M. O., \& Phelan, J. P. (1990). Intrapartum amniotic fluid volume at term. Association of ruptured membranes, oligohydramnios and increased fetal risk. The Journal of reproductive medicine, 35(7), 719-723. 